\title{
TEM and STEM Observations of a Flat Continuous Silicon-Germanium Thin Film Epitaxially Grown on Porous Silicon
}

\author{
Junji Yamanaka1, Noritaka Usami2, Sevak Amtablian³, Alain Fave³, Mustapha Lemiti3, \\ Chiaya Yamamoto ${ }^{4,5}$, Kiyokazu Nakagawa1
}

${ }^{1}$ Center for Crystal Science and Technology, University of Yamanashi, Kofu, Japan

${ }^{2}$ Graduate School of Engineering, Nagoya University, Nagoya, Japan

${ }^{3}$ Institut des Nanotechnologies de Lyon, site INSA-Lyon, Villeurbanne, France

${ }^{4}$ Center for Creative Technology, University of Yamanashi, Kofu, Japan

${ }^{5}$ Center for Instrumental Analysis, University of Yamanashi, Kofu, Japan

Email: jyamanak@yamanashi.ac.jp

How to cite this paper: Yamanaka, J., Usami, N., Amtablian, S., Fave, A., Lemiti, M., Yamamoto, C. and Nakagawa, K. (2017) TEM and STEM Observations of a Flat Continuous Silicon-Germanium Thin Film Epitaxially Grown on Porous Silicon. Journal of Materials Science and Chemical Engineering, 5, 26-34.

http://dx.doi.org/10.4236/msce.2017.51004

Received: November 1, 2016

Accepted: January 1, 2017

Published: January 4, 2017

\begin{abstract}
Strain-relaxed SiGe is an attractive material for use as a substrate of strained $\mathrm{Si}$, in which carrier mobility is higher than that of bulk $\mathrm{Si}$. The concept of this study is the use of porous $\mathrm{Si}$ as a sponge like substrate so that a SiGe lattice can relax without introducing dislocations. We produced porous Si specimens by electrochemical anodization and annealed them under a $\mathrm{H}_{2}$ atmosphere. Then, SiGe thin films were grown by gas-source molecular beam epitaxy. We observed the microstructure of the specimens using transmission electron microscopy. The result showed that we succeeded in producing a single-crystal continuous $\mathrm{Si}_{0.73} \mathrm{Ge}_{0.27}$ film with a $10 \%$ relaxation ratio and a low dislocation density on porous $\mathrm{Si}$.
\end{abstract}

\section{Keywords}

Porous Silicon, Silicon Germanium, Strain Relaxation, Strained Silicon, Nanostructure, High-Mobility Semiconductors, Transmission Electron Microscopy

\section{Introduction}

Operation speed of field effect transistors (FETs) have mainly been developed by downsizing them, but their properties are now almost saturated. Therefore, we now have to develop a new device made of high-mobility materials. Strained $\mathrm{Si}$ is attracting tremendous interest from this viewpoint because of its high carrier 
mobility. SiGe is the most promising substrate for forming a strained Si thin film because SiGe has the same crystal structure as $\mathrm{Si}$ and we can control its lattice constant by changing its Ge composition.

One approach being investigated is the single-crystal growth of bulk SiGe [1] [2] [3]. Presently, the main focus is to produce a strain-relaxed SiGe thin film on a $\mathrm{Si}$ substrate because we can use current industrial processes without major changes. Thus, many research groups have proposed and examined new methods of producing strain-relaxed $\mathrm{SiGe} / \mathrm{Si}$, such as, composition-graded $\mathrm{SiGe}$ buffer, SiGe growth on a low-temperature Si buffer, and ion implantation before, during, or after the SiGe growth [4]-[20]. The common sense of these three methods is that we must introduce lattice defects to relax the SiGe and we must bury the defects so that they do not appear on the surface.

It would be very useful if we could produce strain-relaxed thin SiGe/Si without introducing any defects. Luryi and Suhir reported an interesting calculation showing that $\mathrm{SiGe}$ on porous $\mathrm{Si}$ could have a lower elastic energy than SiGe on bulk $\mathrm{Si}$ because porous $\mathrm{Si}$ behaves as a sponge-like substrate [21]. On the other hand, Xie and Bean reported different result [22].

More recently, Marty et al. reported that strain-relaxed SiGe has been experimentally grown on porous Si [23]. Their TEM result suggested that they had succeeded in forming a highly oriented SiGe crystal on porous $\mathrm{Si}$, however, the SiGe layer might not have been a perfect single crystal.

Our group evaluated the elastic strains of both SiGe and porous Si layers using Raman spectroscopy and demonstrated that porous Si was strained and that $\mathrm{SiGe}$ had a lower strain than SiGe on bulk Si [24]. However, we did not confirm the crystallinity of the specimens at this stage. As a matter of course, both the relaxation ratio and crystallinity are important for the future application to use this specimen as a material of electronic devices. Marty et al. and our group independently succeeded in producing relaxed $\mathrm{SiGe}$ on porous $\mathrm{Si}$; however, to our knowledge, there are as yet no studies on realizing and confirming a relaxed single-crystalline continuous SiGe layer on a porous Si substrate.

In this study, we observed the microstructure of SiGe on porous Si using transmission electron microscopy (TEM), and then clarified the experimental conditions under which both the good crystallinity and high relaxation ratio of SiGe could be achieved simultaneously. In addition, we will also show an example that we could not produce a continuous SiGe layer but a discontinuous one on the porous $\mathrm{Si}$, because the comparison between success and failure must be an important information for other researchers.

\section{Experimental Procedure}

Porous Si was produced by the electrochemical anodization of CZ p+ Si (100) with a resistivity of $0.01 \Omega \cdot \mathrm{cm}$. The electrolytic solution used was HF $(25 \%)+$ $\mathrm{C}_{2} \mathrm{H}_{5} \mathrm{OH}$. We prepared 3- $\mu \mathrm{m}$-thick porous Si layers with porosities of $20 \%$ and $60 \%$. Then we annealed the specimens under a $\mathrm{H} 2$ atmosphere at $1160^{\circ} \mathrm{C}$ for 20 minutes to form a thin continuous Si layer at the surface. (Members of our 
group reported on porous Si used for other purposes, and detailed experimental condition was given in the previous paper [25].)

Then $\mathrm{Si}_{0.73} \mathrm{Ge}_{0.27}$ films were deposited using gas-source molecular beam epitaxy (GS-MBE). The source gases were $\mathrm{Si}_{2} \mathrm{H}_{6}$ and $\mathrm{GeH}_{4}$, and the substrate temperature was $500^{\circ} \mathrm{C}$. The $\mathrm{Si}_{0.73} \mathrm{Ge}_{0.27}$ thickness was approximately $30 \mathrm{~nm}$.

After the GS-MBE growth, we deposited amorphous carbon, Pt-Pd, and W as protection layers to avoid possible defects during thin-film fabrication for TEM observation. Then we fabricated the specimens using a focused ion beam (FIB) to prepare TEM specimens. It is technically very important to prepare flat TEM specimens in this study, the reason will be explained below, so we chose the FIB rather than ion-milling or other techniques. We observed the microstructure of the specimens using two TEM systems: One was a HITACHI HD-2300C scanning transmission electron microscope (STEM) for taking STEM bright-field images (STEM-BFI) and high-angle annular dark field (HAADF) images. HAADF imaging is generally used to observe elemental distributions, but is also useful for observing porous structures because the diffraction contrast is almost negligible. HAADF simply reflects the local thickness if the TEM specimens are macroscopically flat. This is the reason why we used an FIB to prepare TEM specimens. (As a matter of course, we can also verify the elemental distributions by HAADF imaging.) The combined use of an FIB and HAADF imaging is the only way to evaluate porous structures. The other TEM system was a JEOL JEM 2000FX-II conventional TEM system for taking TEM dark-field images (TEMDFIs), TEM-BFIs, and selected-area diffraction patterns (SADPs). Observations using conventional TEM were carried out to precisely observe lattice defects, such as dislocations.

\section{Results and Discussion}

We previously reported the results of the Raman spectroscopy of the relaxed $\mathrm{SiGe}$ on porous $\mathrm{Si}$ [24]. We showed that porous $\mathrm{Si}$ is strained by a $\mathrm{Si}_{0.73} \mathrm{Ge}_{0.27}$ film. We also confirmed that $\mathrm{Si}_{0.73} \mathrm{Ge}_{0.27}$ is relaxed by approximately $10 \%$ on the $20 \%$-porosity porous $\mathrm{Si}$ and by approximately $50 \%$ on $40 \%$ - and $60 \%$-porosity porous Si. In this study, we focused the two typical cases: SiGe on $20 \%$-porosity porous $\mathrm{Si}$ and $\mathrm{SiGe}$ on $60 \%$-porosity porous $\mathrm{Si}$.

Figure 1 shows the TEM results of the $\mathrm{Si}_{0.73} \mathrm{Ge}_{0.27}$ film on a $\mathrm{Si}(100)$ wafer which we prepared for comparison. Figure $1(\mathrm{a})$ is a cross-sectional HAADF image. It shows that a uniform $\mathrm{Si}_{0.73} \mathrm{Ge}_{0.27}$ layer was formed on the $\mathrm{Si}(100)$ wafer. Figure 1(b) and Figure 1(c) are a TEM-BFI and a TEM-DFI, respectively. The images show that there are some defects such as dislocations in $\mathrm{Si}_{0.73} \mathrm{Ge}_{0.27}$ film and at the interface between the film and the substrate; however, the defect density is not high. This suggests that the $\mathrm{Si}_{0.73} \mathrm{Ge}_{0.27}$ film on the $\mathrm{Si}$ (100) wafer was strained. This result agrees with the fact that $\mathrm{Si}_{0.73} \mathrm{Ge}_{0.27}$ is strained on a $\mathrm{Si}$ wafer, as we previously determined by Raman spectroscopy [24].

Figure 2 shows a cross-sectional HAADF image of $\mathrm{Si}_{0.73} \mathrm{Ge}_{0.27} / 20 \%$-porosity porous Si. This entire image shows that the thickness of the porous Si was $3 \mu \mathrm{m}$, 


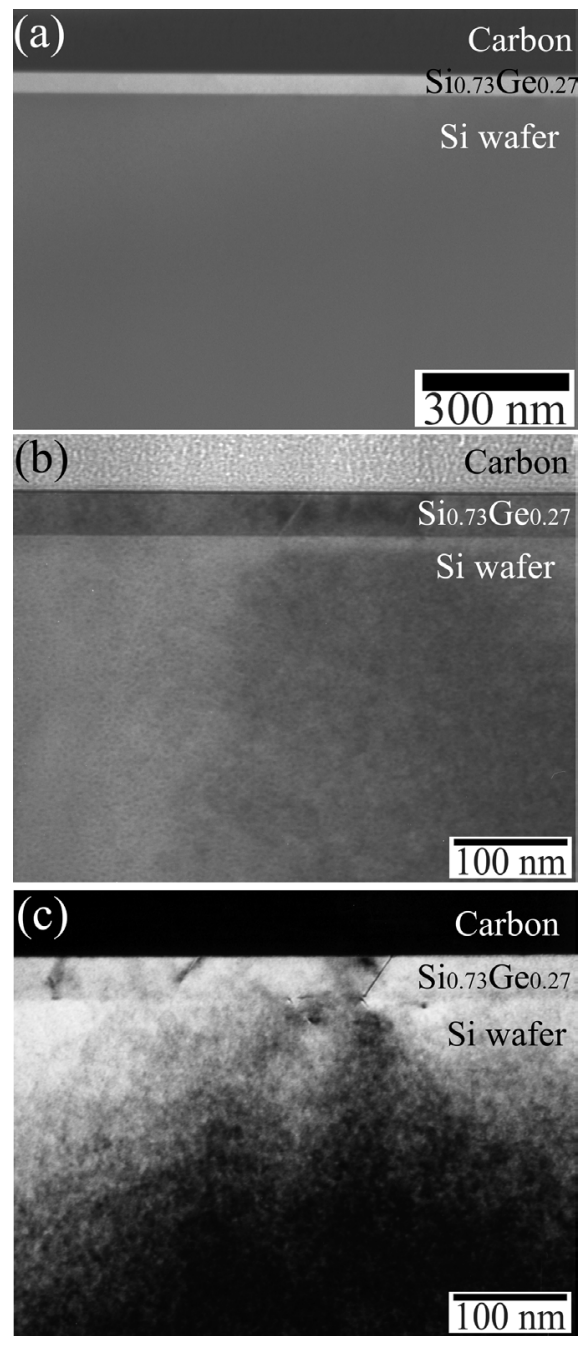

Figure 1. Cross-sectional observations of $\mathrm{Si}_{0.73} \mathrm{Ge}_{0.27}$ film on $\mathrm{Si}(100)$ wafer. HAADF image (a), TEM-BFI (b), and TEM-DFI (c).

as designed, and that we succeeded in producing a flat continuous $\mathrm{Si}_{0.73} \mathrm{Ge}_{0.27}$ film over a very large region on the porous layer.

Figures 3-5 show the results of more detailed observations of $\mathrm{Si}_{0.73} \mathrm{Ge}_{0.27} /$ $20 \%$-porosity porous Si. Figure 3 shows a HAADF image which indicates that thin flat $\mathrm{Si}$ layer exists on top of the porous Si layer and that a flat continuous $\mathrm{Si}_{0.73} \mathrm{Ge}_{0.27}$ layer was grown on it. Figure 4(a) is an SADP from the area which includes both $\mathrm{Si}_{0.73} \mathrm{Ge}_{0.27}$ and porous Si. No extra spots are seen in Figure 4(a); thus, there were no other phases except SiGe and Si. Figure 4(b) is an enlarged SADP. The splitting of the Si 400 spot means that the entire porous Si layer was not a perfect single crystal. It means the porous $\mathrm{Si}$ was partially rotated. However, a SiGe 400 spot were observed on the line of the 000 spot and the Si 400 spot. This means that $\mathrm{Si}_{0.73} \mathrm{Ge}_{0.27}$ was grown epitaxially onto the porous $\mathrm{Si}$ with a parallel orientation relationship. Figure 5(a) and Figure 5(b) are TEM-BFI and TEM-DFI respectively. There are only a few dislocations in these images. It is known that the only one image is insufficient for confirming there are no defects; 


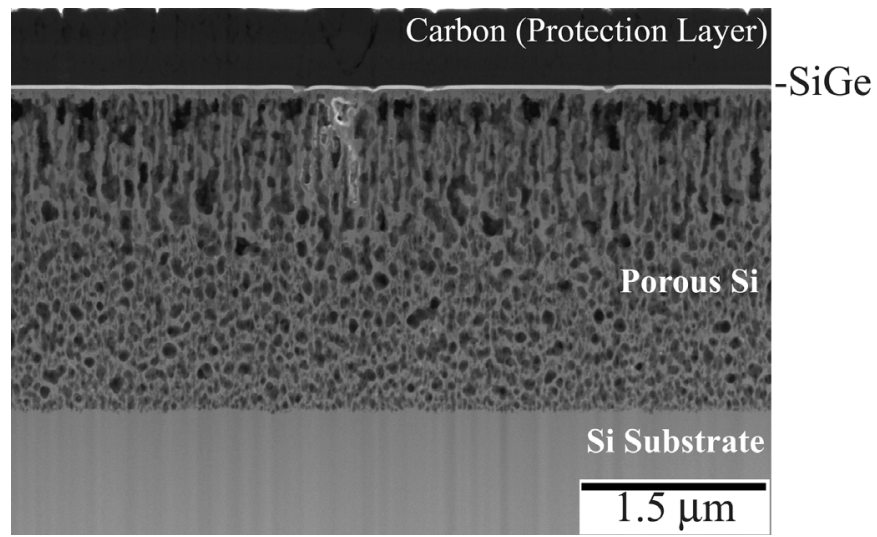

Figure 2. Large-area cross-sectional HAADF image of $\mathrm{Si}_{0.73} \mathrm{Ge}_{0.27} /$ $20 \%$-porosity porous $\mathrm{Si}$.

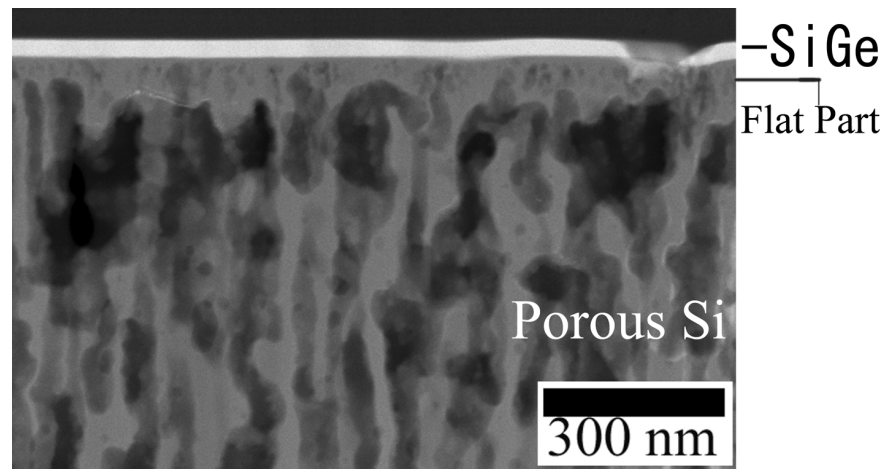

Figure 3. Higher-magnification cross-sectional HAADF image of $\mathrm{Si}_{0.73} \mathrm{Ge}_{0.27} / 20 \%$-porosity porous $\mathrm{Si}$.

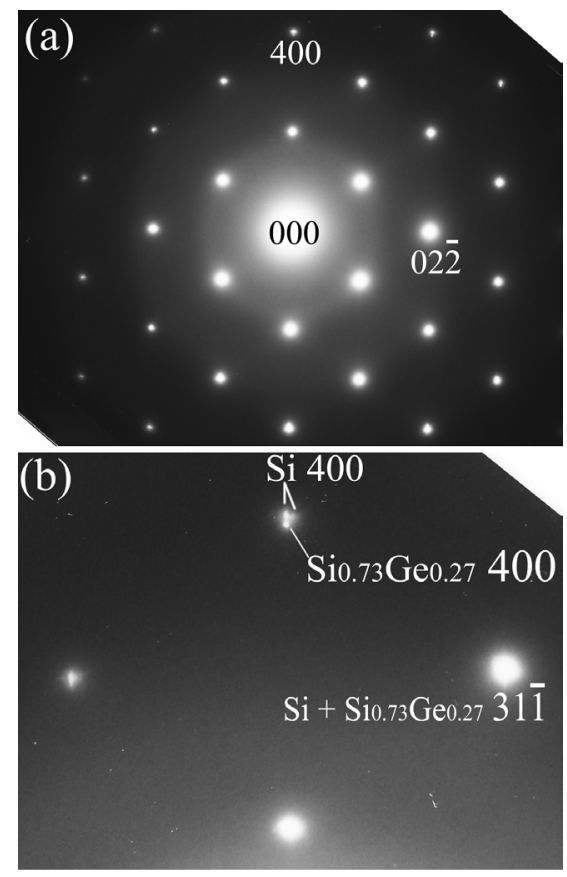

Figure 4. Selected-area diffraction patterns from region of $\mathrm{Si}_{0.73} \mathrm{Ge}_{0.27}$ and $20 \%$-porosity porous Si. Overall pattern (a), and enlarged pattern (b). 


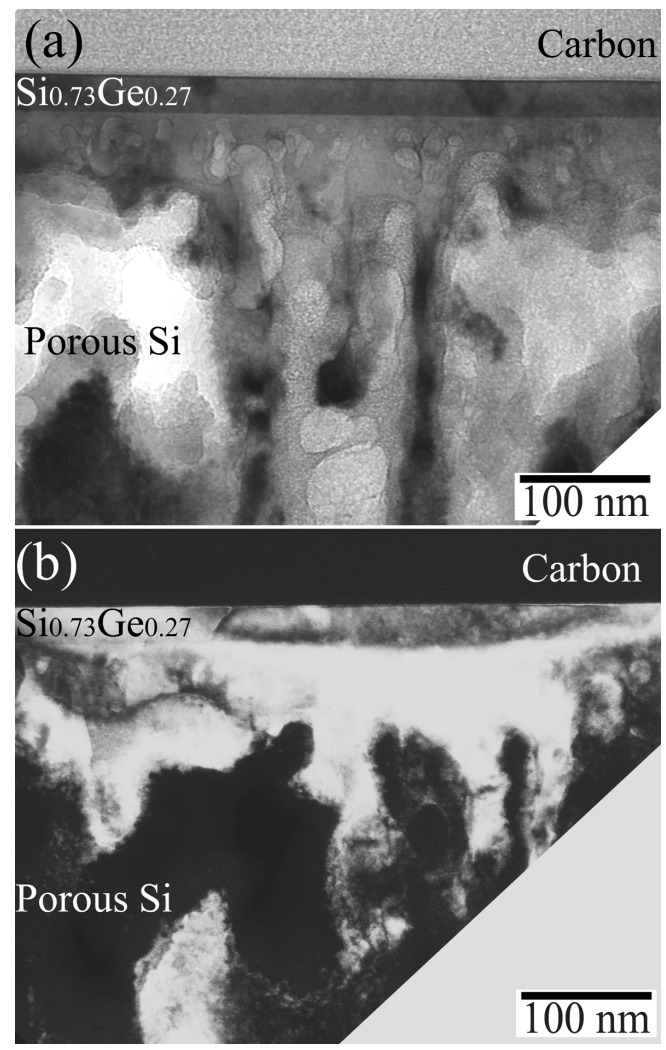

Figure 5. Cross-sectional TEM observations of $\mathrm{Si}_{0.73} \mathrm{Ge}_{0.27} / 20 \%$-porosity porous $\mathrm{Si}$. TEM-BFI (a) and TEM-DFI (b). A continuous single crystal SiGe layer was successively grown onto the porous Si layer in this case.

therefore, we took other images under different excitation conditions, but all of them showed the same results. Therefore, we confirmed that the defect density of $\mathrm{Si}_{0.73} \mathrm{Ge}_{0.27} / 20 \%$-porosity porous $\mathrm{Si}$ is quite low and similar to that of the strained $\mathrm{Si}_{0.73} \mathrm{Ge}_{0.27} / \mathrm{Si}$ (100) shown in Figure 1. We emphasize that $\mathrm{Si}_{0.73} \mathrm{Ge}_{0.27} /$ $20 \%$-porosity porous Si exhibited a $10 \%$ relaxation ratio [24]. It is clear that the origin of the $\mathrm{Si}_{0.73} \mathrm{Ge}_{0.27}$ relaxation in this specimen is not the effect of dislocations. The TEM results of this study and the results of our previous analysis by Raman spectroscopy confirmed that the SiGe relaxation is due to the strain of the porous Si layer [24].

We also observed the microstructure of $\mathrm{Si}_{0.73} \mathrm{Ge}_{0.27} / 60 \%$-porosity porous $\mathrm{Si}$, which exhibited a very high relaxation ratio, i.e., 50\%, in our previous work [24]. Figure 6(a) shows a cross-sectional HAADF image of $\mathrm{Si}_{0.73} \mathrm{Ge}_{0.27} / 60 \%$-porosity porous $\mathrm{Si}$. It shows that the continuity of the surface of porous $\mathrm{Si}$ is not perfect. Figure 6(b) shows a higher-magnification HAADF image. From the contrast of this image and from results of an energy-dispersive X-ray spectroscopy (EDX) profile, which is not shown here, we assumed that the lined part in Figure 6(b) was the $\mathrm{Si}_{0.73} \mathrm{Ge}_{0.27}$. It is obvious that the $\mathrm{Si}_{0.73} \mathrm{Ge}_{0.27}$ layer is not continuous and that this specimen is not suitable for device applications, even though it exhibited a high relaxation ratio in our previous work [24]. 

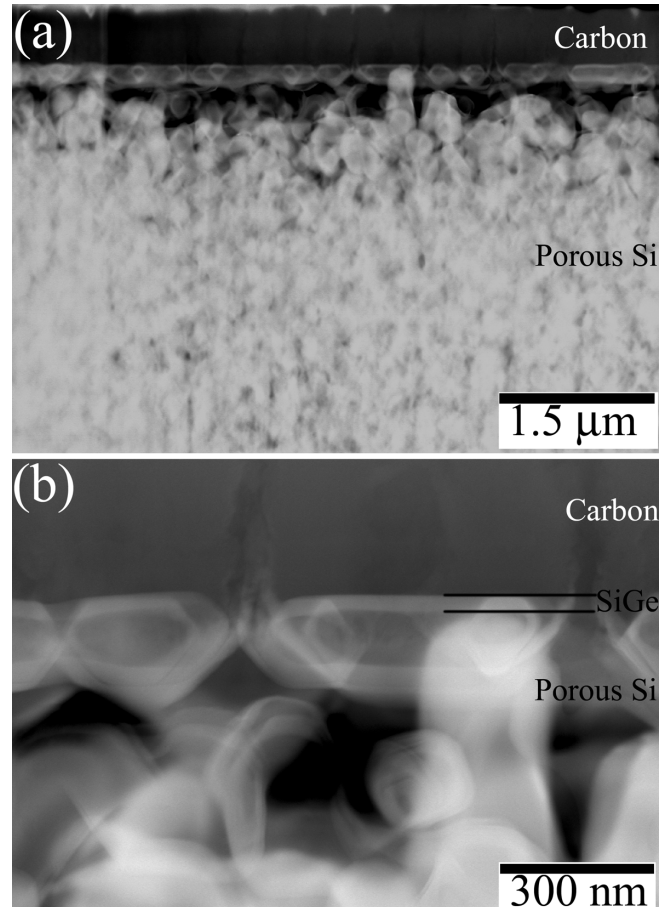

Figure 6. Cross-sectional HAADF images of $\mathrm{Si}_{0.73} \mathrm{Ge}_{0.27} / 60 \%$-porosity porous $\mathrm{Si}$. The lined part in image (b) is assumed to be a part of discontinuous $\mathrm{Si}_{0.73} \mathrm{Ge}_{0.27}$. Continuous $\mathrm{SiGe}$ could not be formed in this case.

The continuity of the SiGe layer depends on the quality of the porous Si surface. As observed in Figure 3, annealing at $1160^{\circ} \mathrm{C}$ under $\mathrm{H}_{2}$ of the $20 \%$-porosity porous $\mathrm{Si}$ provides a thin monocrystalline layer well-suited for obtaining continuous epitaxial layers. It has been shown that porous silicon structures evolve differently depending on the porosity, annealing time, and temperature [26]. Since our two specimens ( $20 \%$ and $60 \%$ porosities) were annealed under the same conditions $\left(1160^{\circ} \mathrm{C}\right.$ for $\left.20 \mathrm{~min}\right)$, improvement can be expected with the use of optimum parameters for the $60 \%$-porosity specimen. Specific porous layer thickness, annealing time, and annealing temperature must be determined for each porosity specimen.

\section{Summary}

$\mathrm{Si}_{0.73} \mathrm{Ge}_{0.27}$ thin films were grown onto annealed porous $\mathrm{Si}$ and their microstructure was observed. Multiple and overall observations using an FIB, HAADF imaging, and conventional TEM enabled us to evaluate both the porous structure and crystallinity of the films.

The experimental results showed that we succeeded in producing a singlecrystal continuous $\mathrm{Si}_{0.73} \mathrm{Ge}_{0.27}$ film on porous $\mathrm{Si}$ with a porosity of $20 \%$, although $\mathrm{SiGe}$ became discontinuous when we used higher-porosity substrates. The $\mathrm{Si}_{0.73} \mathrm{Ge}_{0.27}$ on $20 \%$-porosity porous $\mathrm{Si}$ satisfied all the requirements as a virtual substrate for a strained $\mathrm{Si}$; a flat surface, a $10 \%$ relaxation ratio, and a low dislo- 
cation density. This is an interesting result because the SiGe lattice relaxation mechanism is not due to the normal mechanism of the introduction of dislocations, but due to the unique mechanism of the strain of porous Si. We consider this procedure to have great potential for future applications.

\section{Acknowledgements}

Part of this work was financially supported by the Japan-France integrated action program "SAKURA" from the Japan Society for the Promotion of Science (JSPS), the Ministère des Affaires Etrangères in France (MAE), and the Ministère del'Education Nationale, de l'Enseignement Supérieur et de la Recherche. We thank Dr. Keisuke Arimoto for useful suggestions.

\section{References}

[1] Nakajima, K., Kusunoki, T., Azuma, Y., Usami, N., Fujiwara, K., Ujihara, T., Sazaki, G. and Shishido, T. (2002) J. Cryst. Growth, 240, 373-381. https://doi.org/10.1016/S0022-0248(02)00940-5

[2] Azuma, Y., Usami, N., Ujihara, T., Fujiwara, K., Sazaki, G., Murakami, Y. and Nakajima, K. (2003) J. Cryst. Growth, 250, 298-304. https://doi.org/10.1016/S0022-0248(02)02400-4

[3] Usami, N., Kitamura, M., Obara, K., Nose, Y., Shishido, T. and Nakajima, K. (2005) J. Cryst. Growth, 284, 57-64. https://doi.org/10.1016/j.jcrysgro.2005.06.060

[4] Baribeau, J.M., Jackman, T.E., Houghton, D.C., Maigné, P. and Denhoff, M.W. (1988) J. Appl. Phys., 63, 5738-5746. https://doi.org/10.1063/1.340312

[5] Fitzgerald, E.A., Xie, Y.-H., Green, M.L., Brasen, D., Kortan, A.R., Michel, J., Mii, Y.-J. and Weir, B.E. (1991) Appl. Phys. Lett., 59, 811-813. https://doi.org/10.1063/1.105351

[6] LeGoues, F.K., Meyerson, B.S., Morar, J.F. and Kirchner, P.D. (1992) J. Appl. Phys., 71, 4230-4243. https://doi.org/10.1063/1.350803

[7] LeGoues, F.K. (1994) Phys. Rev. Lett., 72, 876-879. https://doi.org/10.1103/PhysRevLett.72.876

[8] Mooney, P.M., Jordan-Sweet, J.L., Ismail, K., Chu, J.O., Feenstra, R.M. and LeGoues, F.K. (1995) Appl. Phys. Lett., 67, 2373-2375. https://doi.org/10.1063/1.114349

[9] Chen, H., Guo, L.W., Cui, Q., Hu, Q., Huang, Q. and Zhou, J.M. (1996) J. Appl. Phys., 79, 1167-1169. https://doi.org/10.1063/1.360899

[10] Li, J.H., Peng, C.S., Wu, Y., Dai, D.Y., Zhou, J.M. and Mai, Z.H. (1997) Appl. Phys. Lett., 71, 3132-3134. https://doi.org/10.1063/1.120268

[11] Ueno, T., Irisawa, T., Shiraki, Y., Uedono, A. and Tanigawa, S. (2000) Thin Solid Films, 369, 320-323. https://doi.org/10.1016/S0040-6090(00)00872-5

[12] Trinkaus, H., Holländer, B., Rongen, St., Mantl, S., Herzog, H.-J., Kuchenbecker, J. and Hackbarth, T. (2000) Appl. Phys. Lett., 76, 3552-3554. https://doi.org/10.1063/1.126704

[13] Luysberg, M., Kirch, D., Trinkaus, H., Holländer, B., Lenk, St., Mantl, S., Herzog, H.-J., Hackbarth, T. and Fichtner, P.F.P. (2002) J. Appl. Phys., 92, 4290-4295. https://doi.org/10.1063/1.1504496

[14] Sawano, K., Hirose, Y., Ozawa, Y., Koh, S., Yamanaka, J., Nakagawa, K., Hattori. T. and Shiraki, Y. (2003) Jpn. J. Appl. Phys., 42, L735-737. https://doi.org/10.1143/JJAP.42.L735 
[15] Yamanaka, J., Sawano, K., Nakagawa, K., Suzuki, K., Ozawa, Y., Koh, S., Hattori, T. and Shiraki, Y. (2004) Mater. Trans., 45, 2644-2646. https://doi.org/10.2320/matertrans.45.2644

[16] Sawano, K., Koh, S., Shiraki, Y., Ozawa, Y., Hattori, T., Yamanaka, J., Suzuki, K., Arimoto, K., Nakagawa, K. and Usami, N. (2004) Appl. Phys. Lett., 85, 2514-2516. https://doi.org/10.1063/1.1794353

[17] Yamanaka, J., Sawano, K., Nakagawa, K., Suzuki, K., Ozawa, Y., Koh, S., Hattori, T. and Shiraki, Y. (2004) Mater. Sci. Semicond. Process, 7, 389-392. https://doi.org/10.1016/j.mssp.2004.09.008

[18] Bauer, M., Oehme, M., Lyutovich, K. and Kasper, E. (1998) Thin Solid Films, 336, 104-108. https://doi.org/10.1016/S0040-6090(98)01274-7

[19] Kasper, E., Lyutovich, K., Bauer, M. and Oehme, M. (1998) Thin Solid Films, 336, 319-322. https://doi.org/10.1016/S0040-6090(98)01317-0

[20] Yamanaka, J., Sawano, K., Suzuki, K., Nakagawa, K., Ozawa, Y., Hattori, T. and Shiraki, Y. (2006) Thin Solid Films, 508, 103-106. https://doi.org/10.1016/j.tsf.2005.08.392

[21] Luryi, S. and Suhir, E. (1986) Appl. Phys. Lett., 49, 140-142. https://doi.org/10.1063/1.97204

[22] Xie, Y.H. and Bean, J.C. (1990) J. Vac. Sci. Technol., B8, 227-231. https://doi.org/10.1116/1.584815

[23] Marty, O., Nychyporuk, T., de la Torre, J., Lysenko, V., Bremond, G. and Barbier, D. (2006) Appl. Phys. Lett., 88, 101909-1-101909-3. https://doi.org/10.1063/1.2179620

[24] Usami, N., Kutsukake, K., Nakajima, K., Amtablian, S., Fave, A. and Lemiti, M. (2007) Appl. Phys. Lett., 90, 031915-1 -031915-3.

[25] Fave, A., Quoizola, S., Kraiem, J., Kaminski, A., Lemiti, M. and Laugier, A. (2004) Thin Solid Films, 451-452, 308-311. https://doi.org/10.1016/j.tsf.2003.11.055

[26] Ott, N., Nerding, M., Müller, G., Brendel, R. and Strunk, H.P. (2003) Phys. Status Solidi A, 197, 93-97. https://doi.org/10.1002/pssa.200306474

\section{Submit or recommend next manuscript to SCIRP and we will provide best service for you:}

Accepting pre-submission inquiries through Email, Facebook, LinkedIn, Twitter, etc. A wide selection of journals (inclusive of 9 subjects, more than 200 journals)

Providing 24-hour high-quality service

User-friendly online submission system

Fair and swift peer-review system

Efficient typesetting and proofreading procedure

Display of the result of downloads and visits, as well as the number of cited articles

Maximum dissemination of your research work

Submit your manuscript at: http://papersubmission.scirp.org/

Or contact msce@scirp.org 